\title{
Fatal Human Infection with Evidence of Intrahost Variation of Eastern Equine Encephalitis Virus, Alabama, USA, 2019
}

Holly R. Hughes, Jason O. Velez, Emily H. Davis, Janeen Laven, Carolyn V. Gould, Amanda J. Panella, Amy J. Lambert, J. Erin Staples, Aaron C. Brault

Eastern equine encephalitis virus (EEEV) is an arbovirus in the family Togaviridae, genus Alphavirus, found in North America and associated with freshwater/hardwood swamps in the Atlantic, Gulf Coast, and Great Lakes regions. EEEV disease in humans is rare but causes substantial illness and death. To investigate the molecular epidemiology and microevolution of EEEV from a fatal case in Alabama, USA, in 2019, we used next-generation sequencing of serum and cerebrospinal fluid (CSF). Phylogenetic inference indicated that the infecting strain may be closely related to isolates from Florida detected during 2010-2014, suggesting potential seeding from Florida. EEEV detected in serum displayed a higher degree of variability with more single-nucleotide variants than that detected in the CSF. These data refine our knowledge of EEEV molecular epidemiologic dynamics in the Gulf Coast region and demonstrate potential quasispecies bottlenecking within the central nervous system of a human host.

Tn North America, eastern equine encephalitis virus 1 (EEEV) causes disease in equids, domestic birds, and humans $(1,2)$. The virus is maintained in an enzootic cycle between passerine avian amplification hosts and Culiseta melanura mosquitoes as the principal mosquito vectors (3). EEEV infections in humans and equids result from spillover from the enzootic transmission cycle or by the bites of bridge vectors that can become infected during epizootics. In humans and equids, viremia does not develop at sufficient levels to infect additional mosquito vectors; however, the disease can be severe because of the neurotropic nature of the virus (4).

In the New England region, cases of eastern equine encephalitis (EEE) resulting from EEEV infection in

Author affiliation: Centers for Disease Control and Prevention, Fort Collins, Colorado, USA

DOI: https://doi.org/10.3201/eid2707.210315 humans are seasonal and are typically reported during July-October (5); in Florida, EEEV transmission persists all year (6). The first case of EEE in a human was identified in Massachusetts in 1938 after an epizootic among horses (2). Before 2019, the last major EEE epidemic occurred in New Jersey in 1959; a total of 32 cases in humans were reported (7). During 2003-2018, an average of 8 (range 4-21) EEE cases/year in humans were reported to the Centers for Disease Control and Prevention (CDC) (8). Although reports of EEE in humans are rare and the proportion of inapparent infections is high (7), the case-fatality rate for patients with reported cases of neuroinvasive EEE is estimated to be $30 \%$ (9) and the rate of long-term sequalae in survivors is high, making EEEV infections a substantial public health concern. In 2019, an unprecedented epidemic of EEE across the eastern and upper midwestern United States resulted in 38 confirmed cases in humans, most in Massachusetts and Michigan (8).

EEEV is highly genetically conserved; a single major lineage has been circulating since 1933 (10). Phylogenetic studies have shown substantial genetic diversity among isolates of Madariaga virus, the virus most closely related to EEEV (11). A recent study demonstrated more EEEV genetic diversity among strains in Florida, most likely resulting from yearround transmission and more geographic mixing of EEEV than what is seen in northern states (12).

We investigated the molecular epidemiology of EEEV sequences from 1 patient infected with EEEV in Alabama, an area with historically limited genetic information about EEEV. In addition, we evaluated intrahost virus diversity of EEEV in the patient and report genetic diversity of virus in the blood compared with the central nervous system (CNS). All methods followed manufacturer's recommended protocols unless otherwise noted. 


\section{Methods}

\section{The Patient}

The patient was a woman in her 60s who had lymphoma, for which she was receiving rituximab. She was active and working outdoors until September 2019, when she experienced lethargy and malaise. Approximately 1 week after symptom onset, she was found at home unresponsive and was transferred to the hospital. Her evaluation at the hospital indicated suspected viral encephalitis, but test results for numerous viral and bacterial etiologies, including testing of cerebrospinal fluid (CSF) by BioFire panel (BioFire Diagnostics, LLC, https://www.biofiredx. com), were negative; CNS lymphoma also was ruled out. The patient received broad-spectrum antimicrobial drugs and intravenous immunoglobulin, but her condition did not improve. She lapsed into a coma and never regained consciousness. Life support was discontinued, and she died 43 days after initial illness onset.

\section{Samples}

We extracted RNA from $140 \mu \mathrm{L}$ of serum and CSF from the patient by using the QIAamp Viral RNA Mini Kit (QIAGEN, https://www.qiagen.com). We performed real-time reverse transcription PCR (RTPCR) to detect viral RNA from the endemic encephalitic arboviruses, West Nile virus (WNV), and EEEV. We performed EEEV real-time RT-PCR as previously described (13) by using $10 \mu \mathrm{L}$ of RNA and a QuantiTect Probe RT-PCR Kit (QIAGEN).

\section{Library Preparation and Sequencing}

We generated complementary DNA by using the Ovation RNA-Seq System V2 (NuGen, https:// www.nugen.com). For whole-genome sequencing, we used the Ion Torrent Personal Genomic Machine system. We prepared libraries by using the Ion Plus Fragment Library Kit barcoded with the Ion Xpress Barcoding Kit and quantified by using the Ion Library TaqMan Quantitation Kit (all by Thermo Fisher Scientific, https://www.thermofisher.com). We prepared sequencing templates by using the Hi-Q View OT2 kit with the Ion One Touch 2 system (both by Thermo Fisher Scientific) and completed sequencing by using a Hi-Q View Sequencing Kit (Thermo Fisher Scientific). We loaded templated ion sphere libraries onto 318 Chips V2 and sequenced them by using the Ion Torrent PGM system (both by Thermo Fisher Scientific). We deposited virus sequences from this study into GenBank (accession nos. MT782294 and MT782295).

\section{Whole-Genome Analysis}

We loaded Fastq files (quality phred Q>20) into the CLC genomic workbench version 12 (QIAGEN) and assembled genomes by using de novo assembly. We identified viral contigs by using BLAST (https://blast.ncbi.nlm. nih.gov/Blast.cgi) and completed alignments by using the de novo assembled consensus sequences (GenBank accession nos. MT782294 and MT782295) and Bowtie2 version 2.3.4.1 (https://github.com/BenLangmead/ bowtie2) with paired-end, sensitive local parameters. We removed PCR duplicates with MarkDuplicates (Picard Tools; Broad Institute, https://broadinstitute. github.io/picard). We calculated mutational frequency by using custom $\mathrm{R}$ scripts over possible nucleotide variables (A, U, C, G, -) according to the method described by Matsushita et al. (14) and called variants by using default settings of the software LoFreq (v2.0) requiring $2 \%$ frequency with a minimum of 100 reads (15).

We inferred phylogenies by using MEGA v7 (16). We downloaded reference EEEV complete genomes from GenBank (December 4, 2019) and codon aligned complete coding sequences by using ClustalW (16). We completed phylogenetic inference by using a maximum-likelihood algorithm with 1,000 bootstrap replicates and the general time-reversible model with gamma distributed rate variation and invariable sites, as determined by the model fit test in MEGA (https://www.megasoftware.net). We used Bayesian inference with BEAST (https:/ / beast.community) and a Markov chain Monte Carlo approach of 100 million generations to confirm the maximum-likelihood tree topologies.

\section{Results}

\section{Encephalitic Arboviruses in Clinical Samples}

Serum and CSF specimens collected on day 24 of the patient's illness were sent to the CDC Arboviral Diagnostic and Reference Laboratory (Division of VectorBorne Diseases, National Center for Emerging and Zoonotic Infectious Diseases, Fort Collins, CO, USA), for further evaluation of potential arboviral etiologies. Serum was negative for IgM against La Crosse virus, Jamestown Canyon virus, Powassan virus, and EEEV; neutralizing antibodies against EEEV were not detected. Test results for WNV and Saint Louis encephalitis virus IgM performed at another laboratory were reportedly negative. CSF was negative for IgM against Powassan virus and EEEV. Because the patient was receiving rituximab therapy, which can suppress antibody production, real-time RT-PCR testing was performed and found to be negative for WNV RNA; however, EEEV RNA was detected in serum 
and CSF. Quantification cycle $(\mathrm{Cq})$ values were 27.9 (serum) and 20.5 (CSF).

\section{Genomic and Phylogenetic Analyses}

Complete genome sequences of EEEV were obtained from each specimen: serum (520× coverage) and CSF $(2,689 \times$ coverage). The EEEV consensus sequence from the serum shared $99.79 \%$ nt identity with EEEV sequences from Florida isolated in 2010 (GenBank accession no. KU840313) and 2014 (GenBank accession no KU840338). The EEEV consensus sequence from the CSF shared $99.81 \%$ nt identity with these same reference sequences. Maximum-likelihood phylogenetic analysis supported these findings and placed the derived sequences from the serum and CSF in a well-supported clade with EEEV isolated from northern Florida in 2013 and 2014 (Figure 1). These data suggest that the virus sequences obtained in this study are similar to EEEV circulating in the southeastern United States since 2010.

\section{Intrahost Variability of EEEV in Serum and CSF}

Intrahost variability was measured by detecting singlenucleotide variants (SNVs) in each specimen (Table). We detected 19 SNVs in the serum: 11 in the nonstructural genes, 7 in the structural genes, and 1 in the $3^{\prime}$ untranslated region (UTR). Of the $19 \mathrm{SNV}$ s identified in the serum, 4 were synonymous. In contrast, $12 \mathrm{SNVs}$ were identified in the CSF: 3 in the nonstructural genes, 5 in the structural genes, and 4 in the 3 ' UTR. Of the $12 \mathrm{SNVs}$ in the CSF, 1 was synonymous. When comparing the serum and CSF, we identified 4 SNVs in both specimens: 1 synonymous $\mathrm{SNV}$ at position 1322 in nonstructural protein 1 (NSP1), 2 nonsynonymous SNVs at positions 4443 in NSP3 and 9200 in envelope protein 2 (E2), and 1SNV in the 3' UTR at position 11312.

Three consensus nucleotides found in the serum were not found in the CSF; however, the corresponding minor SNV populations at positions 775 (NSP1), 5291 (NSP3), and 8728 (E2) in the serum were detected in the CSF with 100\% frequency. These consensus level viral populations in the serum resulted in 1 synonymous nucleotide substitution at nt 5921 in NSP3 and 2 nonsynonymous changes at 775 in NSP1-I251T and 8728 in E2-L62S compared with sequences from the CSF and reference EEEV isolates (Figure 2, panels A, B). These data suggest intrahost variability on minor viral populations as well as intrahost variability at the consensus level between the specimen sources.

\section{Discussion}

EEEV causes a severe meningoencephalitis in equids, domestic birds, and humans. In 2019, the number of reported cases in humans increased substantially; 38 cases were confirmed, in contrast with the annual average of 8. We confirmed EEEV infection in an immunocompromised person; deep sequencing of the viral RNA directly from the patient's serum and CSF showed genetic relatedness to recent EEEV isolates in

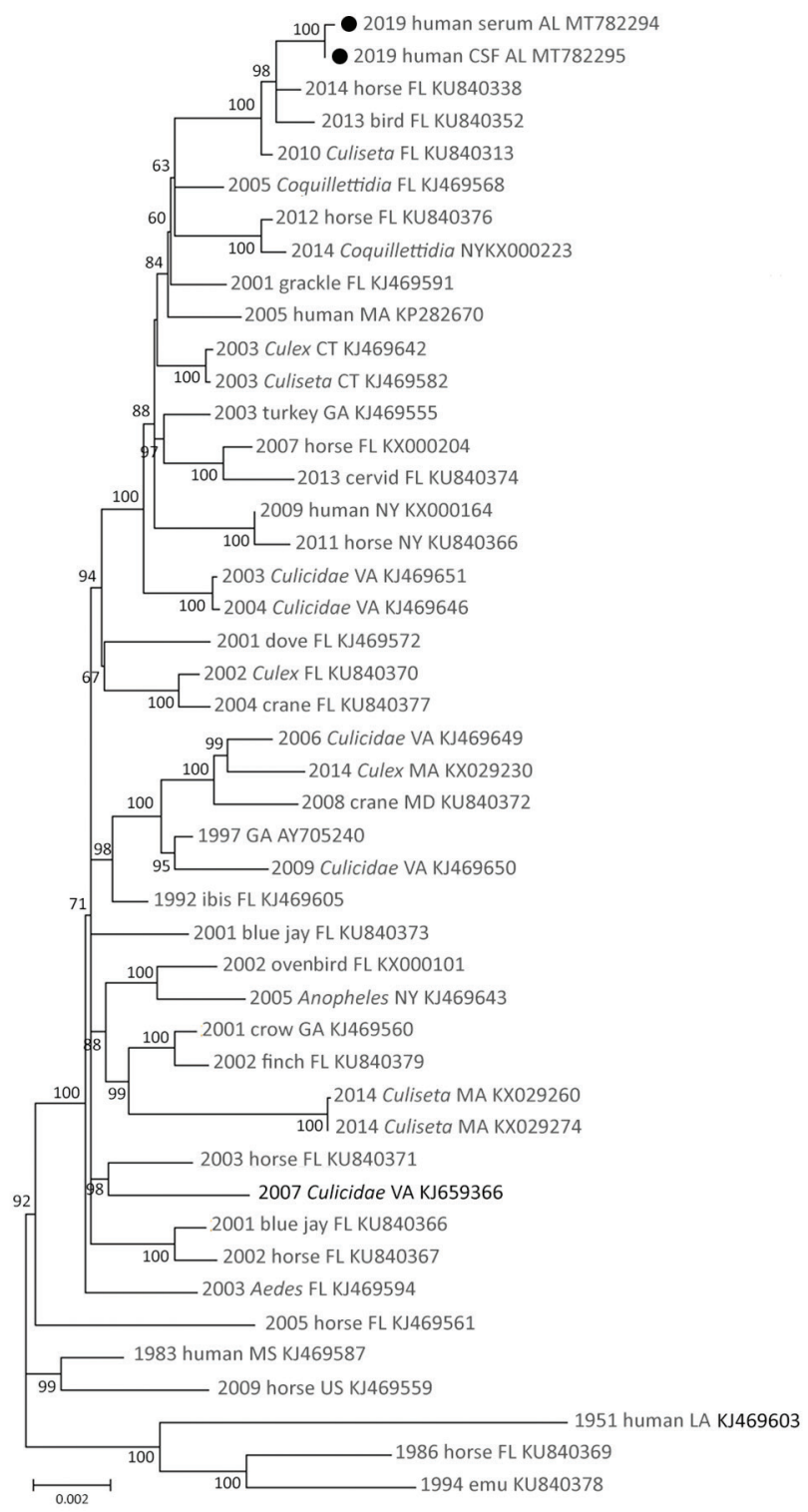

Figure 1. Maximum-likelihood phylogeny of eastern equine encephalitis virus from a woman in Alabama, USA, 2019 (solid circles), and reference sequences, based on complete coding region sequences. Nucleotide coding sequences of the full genome of eastern equine encephalitis viruses isolated during 1951-2019 were codon aligned and phylogenies inferred with general time reversible plus gamma plus proportion of invariable sites. Taxa are labeled with year of isolation, host, US state of isolation, and GenBank accession number. Branches are labeled with bootstrap support values as a percentage of 1,000 replicates. Branches with $<50 \%$ bootstrap support are collapsed; only branches with $>60 \%$ support are labeled. Branch lengths are drawn to scale and measured in the number of substitutions per site. 
Variation of Eastern Equine Encephalitis Virus

Table. Comparison of intrahost variability of eastern equine encephalitis virus variants in serum and cerebrospinal fluid from a woman in Alabama, USA, 2019*

\begin{tabular}{|c|c|c|c|c|c|c|c|}
\hline $\begin{array}{l}\text { Reference } \\
\text { position } \dagger\end{array}$ & $\begin{array}{c}\text { Serum } \\
\text { consensus/SNV }\end{array}$ & $\begin{array}{c}\text { Serum SNV } \\
\text { frequency, \% }\end{array}$ & $\begin{array}{c}\text { CSF } \\
\text { consensus/SNV }\end{array}$ & $\begin{array}{c}\text { CSF SNV } \\
\text { frequency, \% }\end{array}$ & Protein & $\begin{array}{l}\text { Serum SNV amino } \\
\text { acid substitution }\end{array}$ & $\begin{array}{c}\text { CSF SNV aa } \\
\text { substitution }\end{array}$ \\
\hline 646 & $\mathrm{~T} / \mathrm{C}$ & 4.42 & T/- & & NSP1 & I208T & \\
\hline 775 & $\underline{\mathrm{C}} / \mathrm{T}$ & 14.40 & T/- & & NSP1 & T251I & \\
\hline 778 & $\overline{\mathrm{T}} / \mathrm{A}$ & 9.13 & T/- & & NSP1 & L252Q & \\
\hline 1322 & $\mathrm{~T} / \mathrm{C}$ & 12.18 & $\mathrm{~T} / \mathrm{C}$ & 6.52 & NSP1 & P433 & P433 \\
\hline 1326 & $\mathrm{~A} / \mathrm{C}$ & 5.46 & $\mathrm{~A} /-$ & & NSP1 & T435P & \\
\hline 2719 & $\mathrm{~T} /-$ & & $\mathrm{T} / \mathrm{C}$ & 3.23 & NSP2 & & L366P \\
\hline 2866 & $G / A$ & 5.59 & G/- & & NSP2 & $\mathrm{R} 415 \mathrm{H}$ & \\
\hline 2871 & $\mathrm{G} / \mathrm{C}$ & 6.74 & G/- & & NSP2 & $\mathrm{E} 417 \mathrm{Q}$ & \\
\hline 4443 & $\mathrm{~T} / \mathrm{C}$ & 7.75 & $\mathrm{~T} / \mathrm{C}$ & 7.34 & NSP3 & W147R & W147R \\
\hline 4445 & $\mathrm{G} / \mathrm{A}$ & 14.05 & G/- & & NSP3 & W147‡ & \\
\hline 5291 & $\underline{T} / \mathrm{C}$ & 4.21 & $\mathrm{C} /-$ & & NSP3 & A429 & \\
\hline 5546 & $\overline{\mathrm{G}} /-$ & & $G / A$ & 4.87 & Capsid & & T514 \\
\hline 7768 & $\mathrm{C} /-$ & & $\mathrm{A} / \mathrm{C}$ & 6.71 & Capsid & & A66V \\
\hline 7774 & G/- & & G/A & 6.21 & Capsid & & $\mathrm{R} 68 \mathrm{H}$ \\
\hline 8662 & $\mathrm{C} / \mathrm{T}$ & 41.71 & $\mathrm{C} /-$ & & E2 & A40V & \\
\hline 8728 & $\underline{\mathrm{C}} / \mathrm{T}$ & 6.38 & $\mathrm{~T} /-$ & & E2 & S62L & \\
\hline 8827 & $\bar{A} / G$ & 4.17 & $\mathrm{~A} /-$ & & E2 & H95R & \\
\hline 9195 & $A / G$ & 4.29 & $\mathrm{~A} /-$ & & E2 & T218A & \\
\hline 9200 & T/A & 6.37 & T/A & 3.05 & E2 & D219E & D219E \\
\hline 9356 & $\mathrm{~T} / \mathrm{C}$ & 4.49 & T/- & & E2 & P271 & \\
\hline 10603 & $\mathrm{C} /-$ & & $\mathrm{C} / \mathrm{A}$ & 3.81 & $\mathrm{E} 1$ & & T210N \\
\hline 11091 & A/G & 2.72 & $\mathrm{~A} /-$ & & E1 & S373G & \\
\hline 11303 & $\mathrm{~A} /-$ & & $\mathrm{T} / \mathrm{C}$ & 4.82 & 3' UTR & & \\
\hline 11312 & $\mathrm{C} / \mathrm{A}$ & 15.18 & $\mathrm{C} / \mathrm{A}$ & 12.14 & 3' UTR & & \\
\hline 11450 & T/- & & $\mathrm{T} / \mathrm{C}$ & 6.90 & 3' UTR & & \\
\hline 11456 & $\mathrm{C} /-$ & & $A / G$ & 36.61 & 3' UTR & & \\
\hline $\begin{array}{l}\text { *Underlining } \\
\text { protein; SN } \\
\text { †Reference } \\
\text { †Stop codo }\end{array}$ & $\begin{array}{l}\text { consens } \\
\text { ucleotide } \\
\text { osition b }\end{array}$ & tide $\mathrm{cl}$ & m & $\begin{array}{l}\text { dicate } r \\
\text { de239. }\end{array}$ & - & $\begin{array}{l}\text { ebrospinal fluid; NS } \\
\text { e specimens. }\end{array}$ & structural \\
\hline
\end{tabular}

northern Florida and uniquely demonstrated EEEV intrahost variability in a human.

Very few sequences of EEEV isolates from Alabama have been described. The sequences from our study cluster within the FL4 $(12,17)$ monophyletic clade with EEEV isolates from northern Florida collected during 2010-2014. These data support findings of a previous study that evaluated partial coding sequences of 3 isolates from mosquitoes in Alabama that suggest EEEV gene flow between Alabama and Florida (18). Of note, the EEEV sequences derived in our study did not phylogenetically associate with those from similar geographic areas in the Florida panhandle, which have been shown to have a unique spatial structure (17). This finding suggests a potentially complex ecologic association unrelated to geographic proximity. Future surveillance of EEEV in the region will help clarify whether similar FL4 clade strains continue to circulate or become extinct, as has often been observed in northern states (12).

Advances in sequencing have improved our knowledge of intrahost virus variation, or quasispecies, in several arboviruses, including WNV $(19,20)$, dengue viruses (21), Venezuelan equine encephalitis virus $(22,23)$, and Ross River virus (24); however, few studies have evaluated intrahost genetic variation for EEEV (25). Sequencing reads from the serum sample exhibited more viral variation, and sequencing reads from the CSF specimen identified fewer SNVs, especially in coding regions. Our data suggest that EEEV might face a genetic bottleneck between the blood and central nervous system because the genetic variability in the CSF was more limited. The reduction in genetic variability in the CNS could potentially result from a genetic bottleneck and subsequent founder effect because of transmission across the blood-brain barrier as has been observed with poliovirus (26). Alternatively, the genetic variability could be indicative of continued selection for viruses capable of replication in neuronal cells, possibly resulting in neurovirulence (27).

In addition to intrahost quasispecies diversity, we also observed variation in the consensus sequences derived from each specimen. The consensus sequence derived from serum had 2 nonsynonymous nucleotide changes compared with that of the CSF. One amino acid change, NSP1-I251T, is located in an amphipathic peptide that has been shown to play a role in the membrane association of NSP1 (28), possible cell-to-cell transmission, and pathogenicity of alphaviruses $(29,30)$. The second change, E2-L62S, is within the A domain in the wing region (31). This domain has been implicated in neutralization epitopes for several alphaviruses (32-35) and has also been 
demonstrated to be involved with heparin sulfate receptor binding in neuronal cells $(36,37)$.

When evaluating both intrahost virus variants and consensus-level majority variation, we found decreased variation in the CNS is not altogether unexpected because of potential bottlenecks and selection. It is noteworthy that consensus level amino acid changes observed in the serum are not reflected in the CNS. Stochastic generation of virus variants and lack of immune selection cannot explain fixation of 2 nonsynonymous amino acid changes in the peripheral compartment. It is possible that this scenario fits the quasispecies model of cooperative interaction in the virus population as described for poliovirus (38). Applying our observations to the quasispecies model (39) leads to the suggestion that the virus diversity in the periphery could contribute to systematic spread by maintaining the viral subpopulations that might facilitate CNS invasion and replication in this unique compartment. Although this study and observation are limited by a single description of EEEV in human serum, future surveillance and sequencing will add to our knowledge of EEEV disease and virus diversity.

The virus sequences generated in this study were derived from serum and CSF specimens from an immunocompromised person with no detectable serologic

\section{A}

Ruler 1

Consensus

1951_human_LA_KJ469603 1983_human_MS_KJ469587 1986_horse_FL_KU840369 1992_ibis_FL_KJ469605 1994_emu_FL_KU840378 1997_GA_AY705240

2001_blue_jay_FL_KU840373 2001_Blue_Jay_FL_KU840366 2001_crow_GA_KJ469560 2001_dove_FL_KJ469572 2001_grackle_FL_KJ469591 2002_Culex_FL_KU840370 2002_finch_FL_KU840379 2002_horse_FL_KU840367 2003_Aedes_FL_KJ469594 2003_Culex_CT_KJ469642 2003_Culicdae_VA_KJ469651 2003_Culiseta_CT_KJ469582 2003_horse_FL_KU840371 2003_turkey_GA_KJ469555 2004_crane_FL_KU840377 2004_Culicdae_VA_KJ469646 2005_Anopheles_NY_KJ469643 2005_Coquillettidia_FL_KJ469568 2005_horse_FL_KJ469561 2005_human_MA_KP282670 2006_Culicdae_VA_KJ469649 2007_Culicdae_VA_KJ659366 2007_horse_FL_KX000204 2008_crane_MD_KU840372 2009_Culicdae_VA_KJ469650 2009_horse_US_KJ469559 2009_human_NY_KX000164 2010_Culiseta_FL_KU840313 2011_horse_NY_KU840366 2012_horse_FL_KU840376 2013_bird_FL_KU840352 2013_cervid_FL_KU840374 2014_Coquillettidia_NY_KX000223 2014_Culex_MA_KX029230 2014_Culiseta_MA_KX029260 2014_Culiseta_MA_KX029274 2014_horse_FL_KU840338 2019_human_serum_AL_MT782294 2019_human_CSF_AL_MT782295

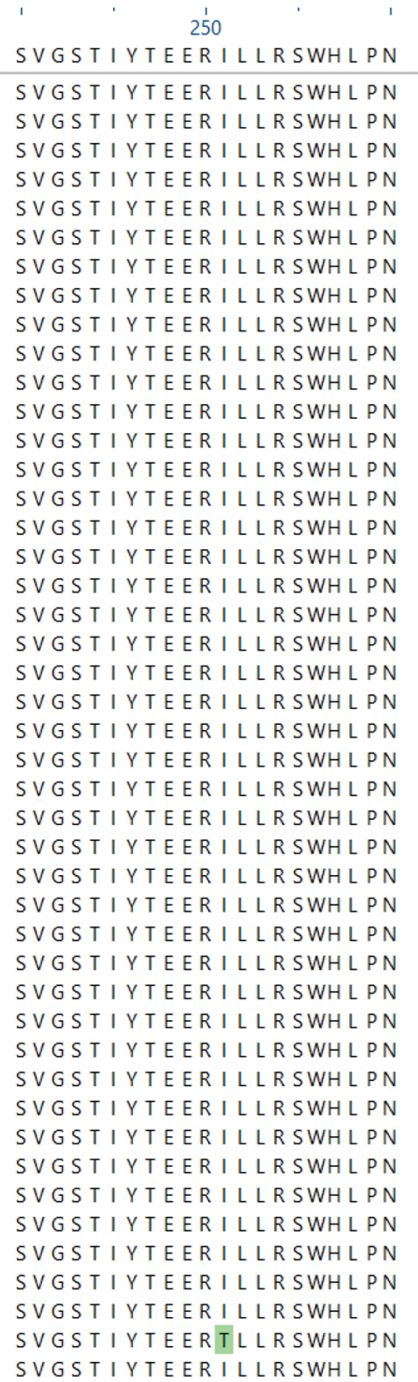

B

Ruler 1

Consensus

2,900

1951_human_LA_KJ469603 1983_human_MS_KJ469587 1986_horse_FL_KU840369 1992_ibis_FL_KJ469605 1994_emu_FL_KU840378 1997_GA_AY705240

2001_blue_jay_FL_KU840373 2001_Blue_Jay_FL_KU840366 2001_crow_GA_KJ469560 2001_dove_FL_KJ469572 2001_grackle_FL_KJ469591 2002_Culex_FL_KU840370 2002_finch_FL_KU840379 2002_horse_FL_KU840367 2003_Aedes_FL_KJ469594 2003_Culex_CT_KJ469642 2003_Culicdae_VA_KJ469651 2003_Culiseta_CT_KJ469582 2003_horse_FL_KU840371 2003_turkey_GA_KJ469555 2004_crane_FL_KU840377 2004_Culicdae_VA_KJ469646 2005_Anopheles_NY_KJ469643 2005_Coquillettidia_FL_KJ469568 2005_horse_FL_KJ469561 2005_human_MA_KP282670 2006_Culicdae_VA_KJ469649 2007_Culicdae_VA_KJ659366 2007_horse_FL_KX000204 2008_crane_MD_KU840372 2009_Culicdae_VA_KJ469650 2009_horse_US_KJ469559 2009_human_NY_KX000164 2010_Culiseta_FL_KU840313 2011_horse_NY_KU840366 2012_horse_FL_KU840376 2013_bird_FL_KU840352 2013_cervid_FL_KU840374 2014_Coquillettidia_NY_KX000223 2014_Culex_MA_KX029230 2014_Culiseta_MA_KX029260 2014_Culiseta_MA_KX029274 2014_horse_FL_KU840338 2019_human_serum_AL_MT782294 2019_human_CSF_AL_MT782295

SAMFGLKTDGVDLAYMSFMNG

SAMFGLKTDGVDLAYMSFMNG

SAMFGLKTDGVDLAYMSFMNG

SAMF GLKTDGVDLAYMS FMNG

SAMFGLKTDGVDLAYMSFMNG

SAMFGLKTDGVDLAYMSFMNG

SAMFGLKTDGVDLAYMSFMNG

SAMFGLKTDGVDLAYMSFMNG

SAMFGLKTDGVDLAYMSFMNG

SAMFGLKTDGVDLAYMSFMNG

SAMFGLKTDGVDLAYMSFMNG

SAMFGLKTDGVDLAYMSFMNG

SAMFGLKTDGVDLAYMSFMNG

SAMFGLKTDGVDLAYMSFMNG

SAMFGLKTDGVDLAYMSFMNG

SAMF GLKTDGVDLAYMSFMNG

SAMFGLKTDGVDLA YMS FMNG

SAMFGLKTDGVDLAYMSFMNG

SAMFGLKTDGVDLAYMSFMNG

SAMFGLKTDGVDLAYMSFMNG

SAMF GLKTDGVDLA YMS FMNG

SAMFGLKTDGVDLAYMSFMNG

SAMFGLKTDGVDLAYMSFMNG

SAMFGLKTDGVDLAYMSFMNG

SAMFGLKTDGVDLAYMSFMNG

SAMFGLKTDGVDLAYMSFMNG

SAMFGLKTDGVDLAYMSFMNG

SAMFGLKTDGVDLAYMSFMNG

SAMFGLKTDGVDLAYMSFMNG

SAMFGLKTDGVDLAYMSFMNG

SAMFGLKTDGVDLAYMSFMNG

SAMFGLKTDGVDLAYMSFMNG

SAMFGLKTDGVDLAYMSFMNG

SAMFGLKTDGVDLAYMSFMNG

SAMFGLKTDGVDLAYMSFMNG

SAMF GLKTDGVDLAYMSFMNG

SAMFGLKTDGVDLAYMSFMNG

SAMFGLKTDGVDLAYMSFMNG

SAMFGLKTDGVDLAYMSFMNG

SAMFGLKTDGVDLA YMS FMNG

SAMFGLKTDGVDLAYMSFMNG

SAMFGLKTDGVDLAYMSFMNG

SAMFGLKTDGVDLAYMSFMNG

SAMFGLKTDGVDSAYMSFMNG

SAMF GLKTDGVDLAYMSFMNG

Figure 2. Amino acid sequence alignments depicting variation in the eastern equine encephalitis virus from a woman in Alabama, USA, 2019, compared with reference viruses. Open reading frames from 46 eastern equine encephalitis virus complete genomes were translated and aligned with ClustalW (16). Amino acid alignments show variants in the 2019 sequence in the nonstructural protein I251T (A) and structural E2 protein L62S (B). Green shading indicates changes unique to the virus sequence obtained from serum compared with cerebrospinal fluid. Reference viruses are labeled with year of isolation, host, state of isolation, and GenBank accession number. 
antibody response to EEEV, probably because of rituximab therapy for lymphoma. Patients receiving B cell-depleting monoclonal antibody therapy may be predisposed to severe neuroinvasive disease and death after arbovirus infection. Cases have been associated with prolonged RNA detection in serum and CSF or brain tissue and lack of serologic response $(40,41)$. This unique circumstance enabled us to sequence EEEV directly from the serum and CSF without amplification and report the complete EEEV sequence derived from human serum. The patient's Cq values of EEEV in serum were low, and viral genome diversity was broad. Although the relative Cq values observed in this study are similar to those found in Cs. melanura mosquitoes with high EEEV titers (42), they are below virus titers that have been observed in experimentally infected birds (43). It is unknown if the viral load in immunocompromised persons could lead to subsequent acquisition and transmission of the virus by a mosquito, but we can speculate that these persons could be hosts for mosquitoborne viruses, given higher viral loads and more prolonged viremias than those observed in dead-end hosts (44-46).

\section{Acknowledgments}

We thank Sherri Davidson and Emily McDonald for helping coordinate the transfer of specimens and relevant patient information.

\section{About the Author}

Dr. Hughes is a research microbiologist in the Diagnostic and Reference Team of the Arboviral Diseases Branch, Division of Vector-Borne Diseases, National Center for Emerging and Zoonotic Infectious Diseases, CDC, Fort Collins, Colorado. Her research focuses on next-generation sequencing and test development for clinical diagnosis.

\section{References}

1. Tully TN Jr, Shane SM, Poston RP, England JJ, Vice CC, Cho DY, et al. Eastern equine encephalitis in a flock of emus (Dromaius novaehollandiae). Avian Dis. 1992;36:808-12. https:/ / doi.org/10.2307/1591790

2. Webster LT, Wright FH. Recovery of eastern equine encephalomyelitis virus from brain tissue of human cases of encephalitis in Massachusetts. Science. 1938;88:305-6. https://doi.org/10.1126/science.88.2283.305

3. Molaei G, Oliver J, Andreadis TG, Armstrong PM, Howard JJ. Molecular identification of blood-meal sources in Culiseta melanura and Culiseta morsitans from an endemic focus of eastern equine encephalitis virus in New York. Am J Trop Med Hyg. 2006;75:1140-7. https://doi.org/10.4269/ ajtmh.2006.75.1140

4. Moncayo AC, Edman JD. Toward the incrimination of epidemic vectors of eastern equine encephalomyelitis virus in Massachusetts: abundance of mosquito populations at epidemic foci. J Am Mosq Control Assoc. 1999;15:479-92.
5. Howard JJ, Morris CD, Emord DE, Grayson MA. Epizootiology of eastern equine encephalitis virus in upstate New York, USA. VII. Virus surveillance 1978-85, description of 1983 outbreak, and series conclusions. J Med Entomol. 1988;25:501-14. https://doi.org/10.1093/jmedent/25.6.501

6. Bigler WJ, Lassing EB, Buff EE, Prather EC, Beck EC, Hoff GL. Endemic eastern equine encephalomyelitis in Florida: a twenty-year analysis, 1955-1974. Am J Trop Med Hyg. 1976;25:884-90. https://doi.org/10.4269/ajtmh.1976.25.884

7. Goldfield M, Welsh JN, Taylor BF. The 1959 outbreak of Eastern encephalitis in New Jersey. 5. The inapparent infection:disease ratio. Am J Epidemiol. 1968;87:32-3. https://doi.org/10.1093/oxfordjournals.aje.a120807

8. Lindsey NP, Martin SW, Staples JE, Fischer M. Notes from the Field: multistate outbreak of eastern equine encephalitis virus - United States, 2019. MMWR Morb Mortal Wkly Rep. 2020;69:50-1. https:// doi.org/10.15585/mmwr.mm6902a4

9. Lindsey NP, Staples JE, Fischer M. Eastern equine encephalitis virus in the United States, 2003-2016. Am J Trop Med Hyg. 2018;98:1472-7. https:/ / doi.org/10.4269/ajtmh.17-0927

10. Arrigo NC, Adams AP, Weaver SC. Evolutionary patterns of eastern equine encephalitis virus in North versus South America suggest ecological differences and taxonomic revision. J Virol. 2010;84:1014-25. https:/ / doi.org/10.1128/JVI.01586-09

11. Brault AC, Powers AM, Chavez CL, Lopez RN, Cachón MF, Gutierrez LF, et al. Genetic and antigenic diversity among eastern equine encephalitis viruses from North, Central, and South America. Am J Trop Med Hyg. 1999;61:579-86. https://doi.org/10.4269/ajtmh.1999.61.579

12. Tan Y, Lam TT, Heberlein-Larson LA, Smole SC, Auguste AJ, Hennigan S, et al. Large-scale complete-genome sequencing and phylodynamic analysis of eastern equine encephalitis virus reveals source-sink transmission dynamics in the United States. J Virol. 2018;92:e00074-18. https://doi.org/10.1128/JVI.00074-18

13. Lambert AJ, Martin DA, Lanciotti RS. Detection of North American eastern and western equine encephalitis viruses by nucleic acid amplification assays. J Clin Microbiol. 2003;41:379_ 85. https:// doi.org/10.1128/JCM.41.1.379-385.2003

14. Matsushita H, Hasegawa K, Oda K, Yamamoto S, Nishijima A, Imai $Y$, et al. The frequency of neoantigens per somatic mutation rather than overall mutational load or number of predicted neoantigens per se is a prognostic factor in ovarian clear cell carcinoma. Oncoimmunology. 2017;6:e1338996. https:// doi.org/10.1080/2162402X.2017.1338996

15. Wilm A, Aw PP, Bertrand D, Yeo GH, Ong SH, Wong CH, et al. LoFreq: a sequence-quality aware, ultra-sensitive variant caller for uncovering cell-population heterogeneity from high-throughput sequencing datasets. Nucleic Acids Res. 2012;40:11189-201. https://doi.org/10.1093/nar/gks918

16. Kumar S, Stecher G, Tamura K. MEGA7: Molecular Evolutionary Genetics Analysis version 7.0 for bigger datasets. Mol Biol Evol. 2016;33:1870-4. https:/ / doi.org/ 10.1093/molbev/msw054

17. Heberlein-Larson LA, Tan Y, Stark LM, Cannons AC, Shilts MH, Unnasch TR, et al. Complex epidemiological dynamics of eastern equine encephalitis virus in Florida. Am J Trop Med Hyg. 2019;100:1266-74. https://doi.org/10.4269/ajtmh.18-0783

18. White GS, Pickett BE, Lefkowitz EJ, Johnson AG, Ottendorfer C, Stark LM, et al. Phylogenetic analysis of eastern equine encephalitis virus isolates from Florida. Am J Trop Med Hyg. 2011;84:709-17. https:// doi.org/10.4269/ajtmh.2011.10-0267

19. Dridi M, Rosseel T, Orton R, Johnson P, Lecollinet S, Muylkens B, et al. Next-generation sequencing shows West Nile virus quasispecies diversification after a single passage in a carrion crow (Corvus corone) in vivo infection model. J Gen Virol. 2015;96:2999-3009. https://doi.org/10.1099/jgv.0.000231 
20. Nelson CW, Sibley SD, Kolokotronis SO, Hamer GL, Newman CM, Anderson TK, et al. Selective constraint and adaptive potential of West Nile virus within and among naturally infected avian hosts and mosquito vectors. Virus Evol. 2018;4:vey013. https://doi.org/10.1093/ve/vey013

21. Ko HY, Li YT, Chao DY, Chang YC, Li ZT, Wang M, et al. Inter- and intra-host sequence diversity reveal the emergence of viral variants during an overwintering epidemic caused by dengue virus serotype 2 in southern Taiwan. PLoS Neg1 Trop Dis. 2018;12:e0006827. https://doi.org/10.1371/ journal.pntd.0006827

22. Patterson EI, Khanipov K, Rojas MM, Kautz TF, Rockx-Brouwer D, Golovko G, et al. Mosquito bottlenecks alter viral mutant swarm in a tissue and time-dependent manner with contraction and expansion of variant positions and diversity. Virus Evol. 2018;4:vey001. https://doi.org/10.1093/ve/vey001

23. Forrester NL, Guerbois M, Adams AP, Liang X, Weaver SC. Analysis of intrahost variation in Venezuelan equine encephalitis virus reveals repeated deletions in the 6-kilodalton protein gene. J Virol. 2011;85:8709-17. https:/ / doi.org/10.1128/JVI.00165-11

24. Liu WJ, Rourke MF, Holmes EC, Aaskov JG. Persistence of multiple genetic lineages within intrahost populations of Ross River virus. J Virol. 2011;85:5674-8. https:/ / doi.org/ 10.1128/JVI.02622-10

25. Weaver SC, Bellew LA, Gousset L, Repik PM, Scott TW, Holland JJ. Diversity within natural populations of eastern equine encephalomyelitis virus. Virology. 1993;195:700-9. https://doi.org/10.1006/viro.1993.1421

26. Pfeiffer JK, Kirkegaard K. Bottleneck-mediated quasispecies restriction during spread of an RNA virus from inoculation site to brain. Proc Natl Acad Sci U S A. 2006;103:5520-5. https://doi.org/10.1073/pnas.0600834103

27. Gardner CL, Ebel GD, Ryman KD, Klimstra WB. Heparan sulfate binding by natural eastern equine encephalitis viruses promotes neurovirulence. Proc Natl Acad Sci U S A. 2011;108:16026-31. https://doi.org/10.1073/ pnas.1110617108

28. Spuul P, Salonen A, Merits A, Jokitalo E, Kääriäinen L, Ahola T. Role of the amphipathic peptide of Semliki Forest virus replicase protein nsP1 in membrane association and virus replication. J Virol. 2007;81:872-83. https:/ / doi.org/10.1128/JVI.01785-06

29. Ahola T, Kujala P, Tuittila M, Blom T, Laakkonen P, Hinkkanen A, et al. Effects of palmitoylation of replicase protein nsP1 on alphavirus infection. J Virol. 2000;74:6725-33. https://doi.org/10.1128/JVI.74.15.6725-6733.2000

30. Laakkonen P, Auvinen P, Kujala P, Kääriäinen L. Alphavirus replicase protein NSP1 induces filopodia and rearrangement of actin filaments. J Virol. 1998;72:10265-9. https:/ / doi.org/10.1128/JVI.72.12.10265-10269.1998

31. Voss JE, Vaney MC, Duquerroy S, Vonrhein C, Girard-Blanc C, Crublet E, et al. Glycoprotein organization of chikungunya virus particles revealed by X-ray crystallography. Nature. 2010;468:709-12. https://doi.org/10.1038/nature09555

32. Kim AS, Austin SK, Gardner CL, Zuiani A, Reed DS, Trobaugh DW, et al. Protective antibodies against Eastern equine encephalitis virus bind to epitopes in domains A and B of the E2 glycoprotein. Nat Microbiol. 2019;4:187-97. https://doi.org/10.1038/s41564-018-0286-4

33. Pal P, Dowd KA, Brien JD, Edeling MA, Gorlatov S, Johnson S, et al. Development of a highly protective combination monoclonal antibody therapy against chikungunya virus. PLoS Pathog. 2013;9:e1003312. https://doi.org/10.1371/journal.ppat.1003312

34. Hasan SS, Sun C, Kim AS, Watanabe Y, Chen CL, Klose T, et al. Cryo-EM structures of eastern equine encephalitis virus reveal mechanisms of virus disassembly and antibody neutralization. Cell Rep. 2018;25:3136-3147.e5. https://doi.org/10.1016/j.celrep.2018.11.067

35. Jin J, Liss NM, Chen DH, Liao M, Fox JM, Shimak RM, et al. Neutralizing monoclonal antibodies block chikungunya virus entry and release by targeting an epitope critical to viral pathogenesis. Cell Rep. 2015;13:2553-64. https:/ / doi.org/10.1016/j.celrep.2015.11.043

36. Bernard KA, Klimstra WB, Johnston RE. Mutations in the E2 glycoprotein of Venezuelan equine encephalitis virus confer heparan sulfate interaction, low morbidity, and rapid clearance from blood of mice. Virology. 2000;276:93-103. https:/ / doi.org/10.1006/viro.2000.0546

37. Lee P, Knight R, Smit JM, Wilschut J, Griffin DE. A single mutation in the E2 glycoprotein important for neurovirulence influences binding of Sindbis virus to neuroblastoma cells. J Virol. 2002;76:6302-10. https:/ / doi.org/ 10.1128/JVI.76.12.6302-631-.2002

38. Vignuzzi M, Stone JK, Arnold JJ, Cameron CE, Andino R. Quasispecies diversity determines pathogenesis through cooperative interactions in a viral population. Nature. 2006;439:344-8. PMID: 16327776

39. Biebricher CK, Eigen M. The error threshold. Virus Res. 2005; 107:117-27. https:// doi.org/10.1016/j.virusres.2004.11.002

40. Solomon IH, Ciarlini PDSC, Santagata S, Ahmed AA, De Girolami U, Prasad S, et al. Fatal eastern equine encephalitis in a patient on maintenance rituximab: a case report. Open Forum Infect Dis. 2017;4:ofx021. https://doi.org/10.1093/ofid/ofx021

41. Solomon IH, Spera KM, Ryan SL, Helgager J, Andrici J, Zaki SR, et al. Fatal Powassan encephalitis (deer tick virus, lineage II) in a patient with fever and orchitis receiving rituximab. JAMA Neurol. 2018;75:746-50. https://doi.org/ 10.1001/jamaneurol.2018.0132

42. Armstrong PM, Andreadis TG. Eastern equine encephalitis virus in mosquitoes and their role as bridge vectors. Emerg Infect Dis. 2010;16:1869-74. https:/ / doi.org/10.3201/ eid1612.100640

43. Komar N, Dohm DJ, Turell MJ, Spielman A. Eastern equine encephalitis virus in birds: relative competence of European starlings (Sturnus vulgaris). Am J Trop Med Hyg. 1999;60:387-91. https:// doi.org/10.4269/ajtmh.1999.60.387

44. de Souza Pereira BB, Darrigo Junior LG, de Mello Costa TC, Felix AC, Simoes BP, Stracieri AB, et al. Prolonged viremia in dengue virus infection in hematopoietic stem cell transplant recipients and patients with hematological malignancies. Transpl Infect Dis. 2017;19:e12721. https://doi.org/10.1111/tid.12721

45. Mateo R, Xiao SY, Guzman H, Lei H, Da Rosa AP, Tesh RB. Effects of immunosuppression on West Nile virus infection in hamsters. Am J Trop Med Hyg. 2006;75:356-62. https:// doi.org/10.4269/ajtmh.2006.75.356

46. Huang C, Slater B, Rudd R, Parchuri N, Hull R, Dupuis M, et al. First isolation of West Nile virus from a patient with encephalitis in the United States. Emerg Infect Dis. 2002;8:136771. https:// doi.org/10.3201/eid0812.020532

Address for correspondence: Holly Hughes, Centers for Disease Control and Prevention, 3156 Rampart Rd, Fort Collins, CO 80521, USA; email: 1tr8@cdc.gov 